\title{
Surgical outcome of jejunum-jejunum intussusception secondary to Rapunzel syndrome: a case report
}

\author{
Martín Adrián Bolívar-Rodríguez (D), Rodolfo Fierro-López, Adrián Pamanes-Lozano, Marcel Antonio Cazarez-Aguilar,
} Benny Alonso Osuna-Wong and José Cándido Ortiz-Bojórquez

\begin{abstract}
Background: Adult intestinal intussusception is a rare condition caused by the mechanical disruption of bowel motility. A bezoar is defined as indigestible material inside the gastrointestinal tract that develops into a trapped mass; the most frequent bezoar is a trichobezoar. When a trichobezoar extends into the small intestine it is defined as Rapunzel's syndrome. Literature describing complications related to this pathology remains scarce.

Case presentation: A 16-year-old Mexican girl presented to our emergency room with acute abdomen and a presumptive diagnosis of intestinal obstruction. Computed tomography was suggestive of intussusception. Surgery confirmed a jejunal-jejunal intussusception with a mass within the gastric cavity extending into her small intestine, corresponding to a trichobezoar. A manual intussusception reduction and a gastrotomy with extraction of the trichobezoar were performed.

Conclusions: We present a case of a jejunum intussusception as a complication of Rapunzel syndrome. Our patient had a favorable outcome after surgical intervention with a manual intussusception reduction, with retrograde displacement of the trichobezoar into the gastric lumen, and a complete extraction through a gastrostomy. Followup included psychiatric evaluation.
\end{abstract}

Keywords: Intestinal intussusception, Rapunzel syndrome, Trichobezoar, Gastrotomy

\section{Background}

Adult intestinal intussusception is a rare condition caused by a mechanical disruption of motility due to an infection, tumor, Meckel's diverticulum, and intestinal duplication among others [1]. A bezoar is defined as undigested material inside the gastrointestinal tract that eventually becomes a trapped mass. Trichobezoars are made up of hair and are associated with psychiatric conditions such as trichophagia and trichotillomania [2]. Trichobezoars are usually progressive in nature and begin in the stomach [3]. Trichobezoars are the most frequent type of bezoar in patients under 30 years of age [4]. Baudamant was the first to report a trichobezoar in 1779 [5]. If the bezoar happens to extend into the small

\footnotetext{
* Correspondence: bolivarmartin64@hotmail.com

Departament of General Surgery, Centro de Investigación y Docencia en Ciencias de la Salud de la Universidad Autónoma de Sinaloa en el Hospital Civil de Culiacán, Culiacán, Mexico
}

intestine, this is termed Rapunzel syndrome as described by Vaughan et al. in 1968 [6]. Rapunzel syndrome presents with symptoms of intestinal obstruction in which there is a gastric trichobezoar with a "tail-like" post-pyloric extension into the small intestine. The diagnosis is confirmed by surgical findings [7].

Most published case reports focus on intestinal obstruction or perforation [2]. However, a few discuss the relationship between intussusception and Rapunzel syndrome [1], as we report in the following case.

\section{Case presentation}

A 16-year-old Mexican girl presented with a 4-day history of epigastric abdominal pain that radiated to the left hypochondrium and was accompanied by abdominal bloating. She reported vomiting approximately 30 times 24 hours after symptom onset. Oral intake of fluids and solid food was impaired, and both flatus and bowel 
movements were absent. She had no history of prior surgical interventions and did not have a history of fever, hematemesis, jaundice, chyluria, or acholic stools.

She was hemodynamically stable on room air with a mild tachycardia of up to 140 beats per minute (bpm). On physical examination she presented no neurological alterations or alopecia. An abdominal examination revealed distention, borborygmi, painful palpation, and involuntary resistance in upper quadrants with rebound tenderness.

She was hemoconcentrated with a hematocrit of 40 and had leukocytosis of $17,560 / \mathrm{mm}^{3}$. A computed tomography of her abdomen and pelvis with intravenously and orally administered contrast showed dilatation of the gastric chamber with a hyperdense beehive pattern (Fig. 1a, b). Dilated small intestine loops with fluid levels and a target image in the jejunum were suggestive of intussusception. Furthermore, findings were compatible with a trichobezoar.

She underwent an exploratory laparotomy. Findings included gastric distention (Fig. 2), a palpable mass that extended from the gastric lumen to the first duodenum section, and a jejuno-jejunal intussusception (Fig. 3), which was liberated through manual revision. The jejunum showed macroscopic signs of inflammation $110 \mathrm{~cm}$ away from the ligament of Treitz. The mass was manually dragged into the duodenum.

A $10 \mathrm{~cm}$ gastrotomy was performed on the anterior portion of the gastric body and a $20 \mathrm{~cm}$-long continuous conglomerate of hair was extracted followed by four smaller fragments which extended to the site of the

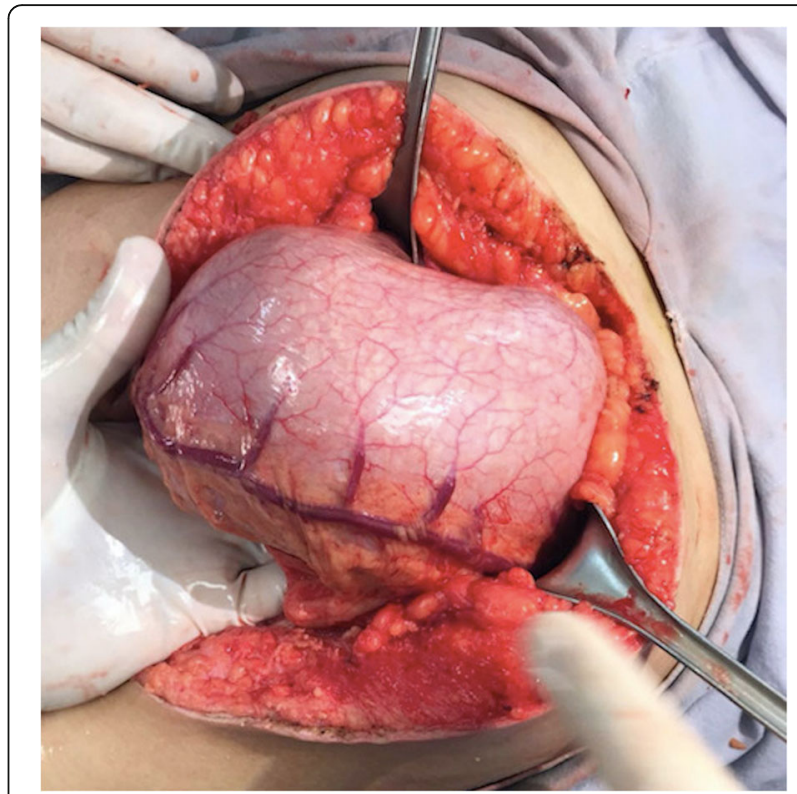

Fig. 2 Anterior wall of the stomach observing dilated gastroepiploic arteries

intussusception (Figs. 4 and 5). After gastric lavage with saline solution, a first intention closure was performed in two layers: first with polyglactin 00 using the Connell technique and then with gastric silk 00 using the Lembert technique. A $19 \mathrm{Fr}$ closed system drainage was placed in her peritoneal cavity.

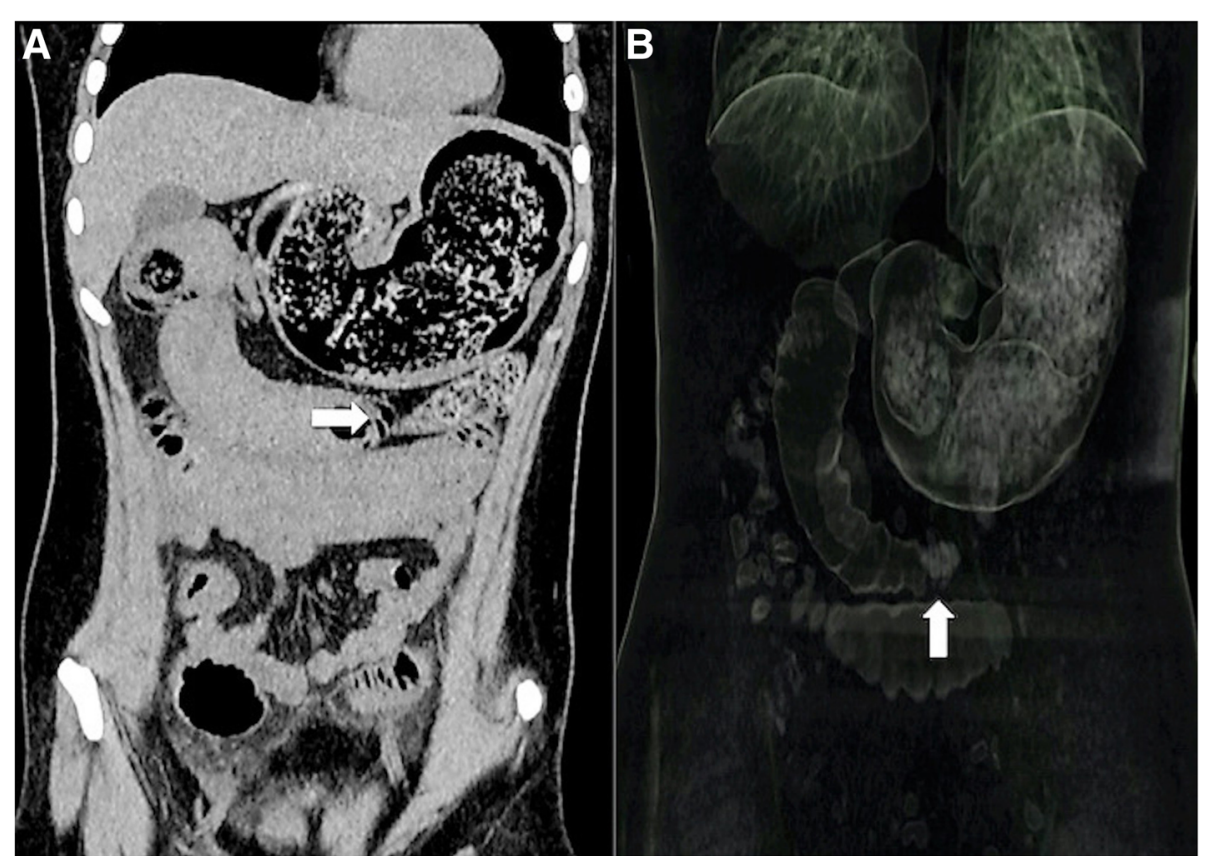

Fig. 1 a Computed tomography with coronal reconstruction, we observe a beehive pattern within the gastric chamber that extends into duodenum, observing a transition zone (arrow) in the proximal jejunum. b Volumetric reconstruction, observing an image suggesting intussusception (arrow) 


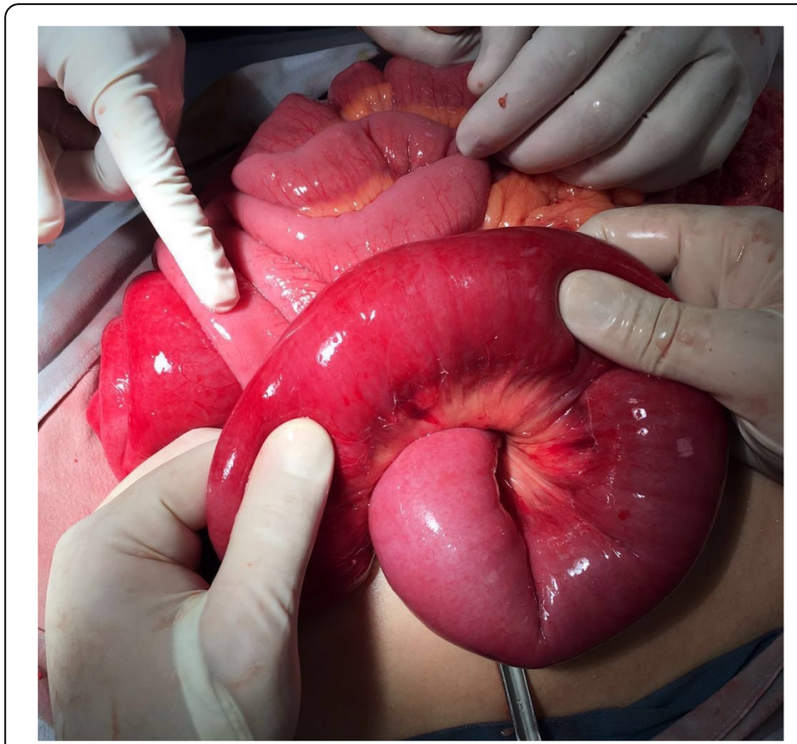

Fig. 3 Jejunum loop with macroscopic changes (edema, swollen, hyperemia) due to intussusception

She had no immediate complications. Enteral nutrition was tolerated during the third postoperative day. Before hospital discharge she was evaluated by an in-house psychiatrist and was discharged during the fifth day of hospital admission.

\section{Discussion}

Bezoars are classified into four groups: phytobezoar (indigestible fiber from fruits and vegetables), trichobezoar (hair), lactobezoar (milk protein/curd), and pharmacobezoar

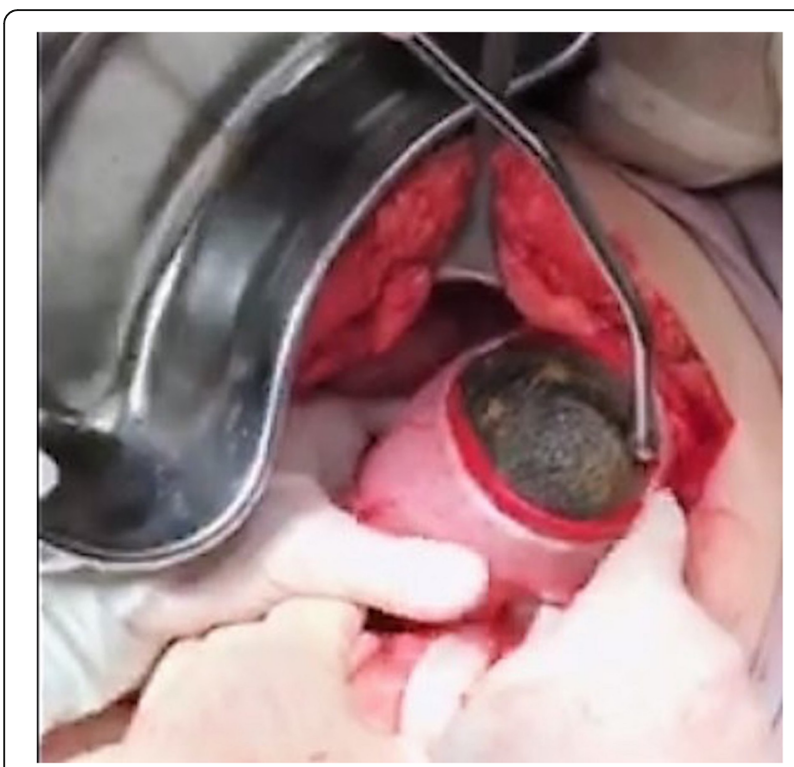

Fig. 4 Trichobezoar extraction through gastrotomy from the anterior gastric wall with a longitudinal incision

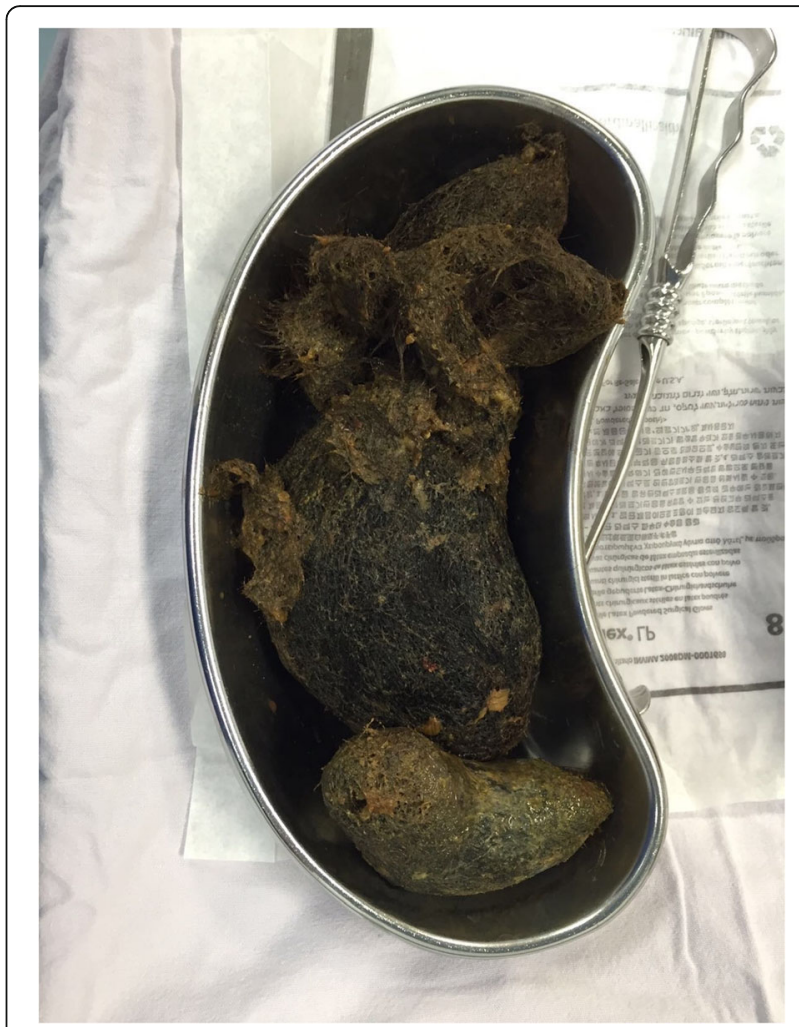

Fig. 5 Extraction of trichobezoar segment

(medications) [8]. The term trichobezoar comes from the Greek word trich, which means hair, and bäzahr, which is Arabic for antidote [9]. Rapunzel's syndrome is a rare form of trichobezoar, which receives its name due to its resemblance to a tail; it has a $1 \%$ incidence in patients with trichophagia [10]. In addition, 90\% of cases involve women with underlying psychiatric disorders [11] and 10\% involve young men [12].

Clinical presentation includes a palpable mass in the abdomen, abdominal pain, nausea, vomiting, weakness, weight loss, diarrhea, malnutrition, anorexia, and constipation depending on the degree of obstruction. The bezoar can cause a mass effect inside the gastrointestinal tract resulting in intestinal obstruction or gastric ulcer. The distal part of the trichobezoar (tail) may interfere with peristalsis and lead to an intussusception [13]. Patients are clinically diagnosed with intestinal obstruction. Medical evidence suggests a 6-month history of trichophagia is necessary in order to become symptomatic.

Image findings include an abdomen X-ray that shows a dilated gastric chamber with a complete filling image displacing intestinal loops. An abdominal ultrasound shows a highly reflective mass inside the stomach and duodenum with posterior acoustic shadowing. The most sensitive diagnostic study is computed tomography with double contrast; it shows gastric dilatation with a 
beehive pattern within that suggests trichobezoar, which extends to the duodenum.

A laparotomy is the surgical intervention of choice for elimination of the trichobezoar. Endoscopic removal remains controversial. Konuma et al. [14] describes a successful 15-minute endoscopic removal of a $34 \mathrm{~cm}, 100 \mathrm{~g}$ trichobezoar. However, a recent literature review by Gorter et al. [15] describes that only 5\% of trichobezoars were susceptible for endoscopic extraction. Furthermore, conservative treatment with fizzy soft drinks has been described [16].

\section{Conclusions}

Surgical management continues to be the treatment of choice for the resolution of a trichobezoar. Enterotomy is the preferred procedure for the extraction of a bezoar with intestinal extension. After extraction a systematic distal examination has to be performed in order to rule out a synchronic bezoar or a distal perforation.

In this case our patient presented Rapunzel syndrome with acute abdomen secondary to an occlusive jejunum-jejunum intussusception. The Rapunzel syndrome was surgically resolved with manual liberation, an anterograde retraction of the trichobezoar into the gastric lumen, and a complete extraction via gastrotomy. Follow-up treatment included psychiatric evaluation.

\section{Acknowledgements}

Not applicable.

Funding

This study did not receive funding.

Availability of data and materials

All data and materials are available in case of request.

\begin{abstract}
Authors' contributions
Authors contributed to this study as follows: MAB-R contributed to the conception and design. RF- $L$ contributed to the writing and acquisition of the data. AP-L contributed to writing. RF-L and JCO-B contributed to the critical revision. BAO-W contributed to the review of literature. MAC-A contributed to the conception and design and critical revision. All authors read and approved the final manuscript.
\end{abstract}

\section{Ethics approval and consent to participate}

Written informed consent was obtained from the patient legal guardians for publication of this case report and any accompanying images. A copy of the written consent is available for review by the Editor-in-Chief of this journal.

\section{Consent for publication}

Written informed consent was obtained from the patient legal guardians for publication of this case report and any accompanying images. A copy of the written consent is available for review by the Editor-in-Chief of this journal.

\section{Competing interests}

The authors declare that they have no competing interests.

\section{Publisher's Note}

Springer Nature remains neutral with regard to jurisdictional claims in published maps and institutional affiliations.
Received: 17 October 2017 Accepted: 16 October 2018

Published online: 07 December 2018

\section{References}

1. Ha S-C, Koh C-C, Lee C-H. A rare case of Rapunzel syndrome with multiple small bowel intussusceptions and bowel obstruction. Formos J Surg. 2016; 49(2):67-9.

2. Prasanna BK, Sasikumar K, Gurunandan U, Sreenath GS, Vikram K. Rapunzel syndrome: a rare presentation with multiple small intestinal intussusceptions. World J Gastrointest Surg. 2013;5(10):282-4

3. Zaraatian S, Ameri S, Tabesh $\mathrm{H}$, Kamalzadeh N. Uncommon presentation of gastric trichobezoar: a case report. Iran J Public Health. 2015;44(7):1008-11.

4. Andrus $\mathrm{CH}$, Ponsky JL. Bezoars: classification, pathophysiology and treatment. Am J Gastroenterol. 1988;83(5):476-8.

5. Filipi CJ, Perdikis G, Hinder RA, DeMeester TR, Fitzgibbons RJ, Peters J. An intraluminal surgical approach to the management of gastric bezoars. Surg Endosc. 1995;9:831-3.

6. Vaughan ED Jr, Sawyers JL, Scott HW Jr. The Rapunzel syndrome. An unusual complication of intestinal bezoar. Surgery. 1968;63(2):339-43.

7. Flaherty DC, Aguilar F, Pradhan B, Grewal H. Rapunzel syndrome due to ingested hair extensions: Surgical and psychiatric considerations. Int J Surg Case Rep. 2015;17:155-7.

8. Czerwinska K, Bekiesinska-Figatowska M, Brzewski M, Gogolewski M, Wolski M. Trichobezoar, Rapunzel syndrome, tricho-plaster bezoar - a report of three cases. Pol J Radiol. 2015;80:241-6.

9. Rabie ME, Arishi AR, Khan A, Ageely H, Seif El-Nasr GA, Fagihi M. Rapunzel syndrome: the unsuspected culprit. World J Gastroenterol. 2008;14(7):1141-3.

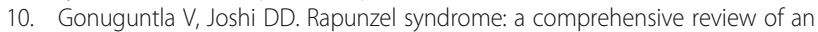
unusual case of trichobezoar. Clin Med Res. 2009;7(3):99-102.

11. Taczalska A, Nowosławska-Łuniewska K, Koziarkiewicz M, Pawlak P, Piaseczna-Piotrowska A. Bezoars diagnostic problems based on own observations and literature review. Med Wieku Rozwoj. 2013;17(3):265-9.

12. Anantha RV, Chadi SA, Merritt N. Trichobezoar causing intussusception: Youngest case of Rapunzel syndrome in a boy in North America. J Ped Surg Rep. 2013;1:e11-3.

13. Morales-Fuentes B, Camacho-Maya U, Coll-Clemente FL, Vazquez-Minero JC. Tricotilomania, tricobezoar de repetición y síndrome de Rapunzel. Informe de un caso y revisión de la literatura. Cir Cir. 2010;78:265-8.

14. Konuma H, Fu K, Morimoto T, Shimizu T, Izumi Y, Shiyanagi S, et al. Endoscopic retrieval of a gastric trichobezoar. World J Gastrointest Endosc. 2011;16;3(1):20-2.

15. Gorter RR, Kneepkens CM, Mattens EC, Aronson DC, Heij HA. Management of trichobezoar: case report and literature review. Pediatr Surg Int. 2010; 26(5):457-63.

16. Iwamuro M, Okada H, Matsueda K, Inaba T, Kusumoto C, Imagawa A, et al. Review of the diagnosis and management of gastrointestinal bezoars. World J Gastrointest Endosc. 2015;7(4):336-45.

Ready to submit your research? Choose BMC and benefit from:

- fast, convenient online submission

- thorough peer review by experienced researchers in your field

- rapid publication on acceptance

- support for research data, including large and complex data types

- gold Open Access which fosters wider collaboration and increased citations

- maximum visibility for your research: over $100 \mathrm{M}$ website views per year

At $\mathrm{BMC}$, research is always in progress.

Learn more biomedcentral.com/submission 